\title{
Ingresos forzados, vocaciones incentivadas y voces desesperadas en el Monasterio de Nuestra Señora de los Remedios de la ciudad de La Plata (Charcas 1574-1640)1
}

\author{
Forced admissions, stimulated vocations, and desperate voices \\ from the Monastery of Nuestra Señora de los Remedios \\ of La Plata (Charcas 1574-1640) \\ Ana María Presta \\ PROHAL, Instituto Ravignani, \\ Universidad de Buenos Aires-CONICET-Argentina \\ ampresta@filo.uba.ar
}

\section{Resumen}

La creación del primer convento de monjas en la sede de la Audiencia de Charcas obedeció a la decisión de la elite que, sobre todo, necesitaba depositar a las huérfanas hijas de conquistadores y a las propias que había decidido no casar. Casa de refugio y solaz para las doncellas con vocación religiosa, Los Remedios también sirvió al ingreso furtivo de quienes habían faltado a la conducta debida a su calidad y al depósito de jóvenes a quienes sus padres, maridos, hermanos o tutores forzaban o incentivaban a convertirse en esposas de Cristo. Se recuperan en este ensayo las voces de mujeres que distaron de ingresar al convento por propia voluntad, abrazando el enclaustramiento por mandato patriarcal y dejando rastro de disconformidad, abandono y esperanza de regresar a la vida en el siglo.

Palabras clave: Monasterio de los Remedios, vocaciones religiosas, ingresos forzados, accesos furtivos, patriarcalismo

\begin{abstract}
The foundation of the first female convent in the seat of the Audiencia de Charcas was driven by the elite that, first and foremost, needed to house the orphan daughters of the conquistadors and their own offspring whom they would not offer a worldly marriage. House of refuge and solace to maids with religious vocation, Los Remedios also served as a furtive entrance to those who openly offended the conduct owed to their calidad and a place to host women who were forced or encouraged by their fathers, husbands, brothers or legal guardians to become the brides of Christ. This essay recovers the voices of women who did not choose to be nuns by their free will and had to embrace claustration following patriarchal obedience while giving testimony of their disagreement, abandonment, and hopes to return to worldly life.
\end{abstract}


Key words: Monastery of Los Remedios, religious vocations, forced professions, furtive access, patriarchalism

Recibido: 10 de junio de 2020 - Aceptado: 09 de julio de 2020

\section{Introducción, propósito y objetivos}

En las últimas tres décadas, los estudios sobre las mujeres y el género desplazaron su mirada a los beaterios, recogimientos y cenobios femeninos a fin de abordar a un colectivo escasamente atendido por la historiografía. La monja emblemática Santa Teresa de Ávila incentivó la historiografía peninsular y su crecimiento en el campo a diferencia de las academias americanas, excepción hecha de México a partir del estudio pionero de Josefina Muriel (1946) sobre los conventos novohispanos. Asunción Lavrin (1973; 1975; 2008) y, más tarde, Rosalva Loreto López (1990a; 1990b; 2000), desarrollaron incontables publicaciones sobre los monasterios mexicanos bajo una perspectiva socioeconómica y cultural, casi siempre situados en la colonialidad tardía, cuyo detalle merece un estudio historiográfico específico. En el caso mexicano, numerosas investigaciones locales e internacionales, y desde distintas vertientes disciplinares, fluyeron hacia el pensamiento, escritura, desarrollo artístico, hábitos, procedencia y educación de las monjas tras la potente figura de sor Juana. Desde la década de 1980, la historiografía sudamericana comenzó por abordar los conventos desde una perspectiva económica, recuperándolos como instituciones abocadas al crédito y la acumulación de propiedades revertidas por sus monjas o donatarios que los convirtieron en el paradigma colonial del préstamo con garantía hipotecaria. Más tarde, desde una perspectiva social y cultural, se escribió sobre las monjas, sus obras corporativas, sus manifestaciones biográficas y hagiográficas y la vida conventual, en general. En el Brasil, el Río de la Plata y los Andes coloniales una serie de investigaciones pioneras, como las de Susan Soeiro $(1974 ; 1978)$ para Salvador de Bahía y Dante Zegarra López (1985) sobre las monjas de Arequipa, precedieron a las de Alicia Fraschina (1999; 2000; 2010), Gabriela Braccio (1999; 2000), Victoria Cohen Imach $(2003 ; 2006)$ y José María Arancibia y Carlos O. Ponza (2014) para los cenobios de Buenos Aires y Córdoba, mientras que Kathryn Burns (1999) y Nancy van Deussen (2001) destacan en el abordaje de los monasterios y recogimientos de Cuzco y Lima². Para los conventos de monjas de Charcas, María Antonia Triano Panadero (1999), Blanca Thórrez (2000; 2001), Emiliano Sánchez Pérez (2011; 2013; 2014) y Aleyda Reyna Reyes (2015) ofrecieron ensayos de escasa difusión sobre los conventos de Santa Clara de La Plata y Los Remedios y Santa Teresa de Potosí, respectivamente. Hasta la fecha, ningún estudio sistemático y de larga data se ha efectuado sobre los tres monasterios de monjas de la ciudad de La Plata, cabecera de la Real Audiencia de Charcas: Nuestra Señora de los Remedios, Santa Clara y Santa Teresa. 
Desde hace tres años estoy abocada al abordaje del primero desde una perspectiva de historia social y de género, tras las que persigo las variables y fundamentos de la dominación en la larga duración. Mi propuesta es observar instituciones, como el convento, que a lo largo de los siglos coloniales concentraron las relaciones de poder y replicaron las desigualdades de clase, etnicidad y género, tras las que se atisban la producción y reproducción de los valores, prácticas y representaciones coloniales. En estaciones de investigación intermedias, surgen temas y problemas que se plasman en contribuciones como la presente, cuyo propósito es develar los ingresos forzados de doncellas y mujeres ligadas a las familias de la elite platense, las cuales desde el último tercio del siglo XVI se involucraron en forma directa en la fundación, administración y vinculación social del Monasterio de los Remedios. Este cenobio femenino fue el primero de los tres fundados en la ciudad de La Plata, también nombrada Chuquisaca o Charcas, hoy Sucre, capital histórica del Estado Plurinacional de Bolivia.

Para abordarlo, cuento con un corpus documental procedente de las Escrituras Públicas de la ciudad de La Pata recuperadas para los siglos XVI y XVII, en tanto la documentación específica de Los Remedios está perdida en su totalidad, excepción hecha de alguna mención fragmentaria en los Libros de Acuerdos de la Real Audiencia de Charcas, en una Visita Eclesiástica a la jurisdicción y los detalles de su fundación que guarda el Archivo General de Indias.

Dado que el cenobio fue fundado por la elite charqueña en 1574, la institución, si bien fue amparada espiritualmente por una orden religiosa, estuvo atada a los jóvenes linajes coloniales y a sus necesidades de consolidación y supervivencia. Por entonces, el estamento privilegiado de Charcas estaba más atento sostener la continuidad de su estatus y a salvaguardar su patrimonio, a lo que contribuyeron sus hijas monjas que, con o sin vocación, ingresaban a un claustro que ayudaba a descomprimir significativas erogaciones dotales, a la vez que a incrementar el prestigio de sus familias.

Las declaraciones voluntarias de profesar resultan elusivas (Sanz de Bremond y Mayáns, 2000: 403), mientras que los registros de los ingresos forzados, aunque escasos, cobran notoriedad por permitir escuchar las voces, desesperadas en ocasiones, de las jóvenes doncellas y, aún, de ciertas señoras casadas cuyos depósitos y toma de votos resultaron inducidos por sus maridos y patrocinantes.

Por lo descripto, previo al abordaje de los ingresos forzados y a fin de asociarlos a los imperativos familiares, sitúo en contexto al convento y a la sociedad temprano colonial que lo estableció.

\section{De la fundación de Los Remedios y el propósito de la elite fundadora}

Siguiendo el propósito de los fundadores, el Monasterio de los Remedios pretendió ser la caja aurea urbana que reuniera a un distinguido grupo de mujeres, cuyas familias prolongaban tras sus paredes su condición de beneméritas de la conquista, resaltando su señorío, mostrando cuidada (a veces inventada) genealogía pero, 
sobre todo, resaltando sus prejuicios frente a las diferentes, en una clara replicación de la sociedad peninsular, fuertemente racializada y situada en la catolicidad (Burns, 2007: 35-39; Hering Torres, 2011a: 35; 2011b: 10, 12, 30-32).

La blanca y silente iglesia situada en la actual intersección de las calles Arenales y Junín, a pasos de la Plaza 25 de Mayo, es un documento histórico que los vecinos de Sucre llaman "Las Mónicas”, y constituye, aparentemente, el único testimonio que permanece en pie del Monasterio de los Remedios de Santa Mónica que un conjunto de vecinos fundó en el último tercio del siglo XVI, luego de largas negociaciones, bajo la supervisión religiosa de la Orden de San Agustín. El cenobio, luego de sufrir avatares tanto económicos como políticos, y sorteando varios intentos de cierre y secularización, extendió su vida religiosa junto a un puñado de monjas hasta 1910, en que los padres de la Compañía de Jesús lo sumaron a su obra educativa junto al Colegio del Sagrado Corazón (Calancha [1639] 1976, III: 1177-1179; García Quintanilla, 1963, III: 147-153; Arancibia, 1868; Mujía, 1887; Berrío, 1909)³. Como habían operado algunos nobles peninsulares a los que pretendían emular, los encomenderos de La Plata, más allá de cegarse por la genealogía y planificar el futuro de su descendencia, encararon la fundación de un convento que, aunque constituyera una empresa dispendiosa (Atienza López, 2010), resaltaba su posición social y proveía de un espacio jerarquizado para el ingreso de las hijas que habían decidido no casar, todo lo cual fluía paralelamente a la construcción de sus linajes (Bruns, 1999: 24). Con esa fundación, la segunda generación de encomenderos buscaba asimismo, por solidaridad y pertenencia de clase, incorporar a las hijas huérfanas de los primeros vecinos que habían fallecido durante las Guerras Civiles (1538-1554) y carecían de recursos suficientes como para ingresar en el selecto mercado matrimonial de Charcas. Aunque la mayoría de esas doncellas cargaba el estigma de la ilegitimidad, dado que habían nacido de la relación formal o casual de sus padres españoles con mujeres indígenas, tenían la posibilidad de emular a las legítimas si sus padres las hubieran reconocido y, vivos o fallecidos, habían proveído a su crianza en su casa o en hogares de españoles, donde se instruyeron en la religión y cultura peninsulares. Esa educación les permitió difuminar el estigma de nacimiento o su "imperfección genealógica" para ser admitidas en la elite, ingresando al mercado matrimonial como si fueran españolas (Martínez, 2008: 61-70, 82-85; Presta, 1997), o al convento, como verdaderas integrantes de la elite.

Asumiendo la fallida experiencia sucesoria de la primera generación sobre su prole en relación con un bien finito como la encomienda, que requería la existencia de heredero legítimo para garantizar su continuidad, los tenedores de indios surgidos luego de las guerras civiles optaron por el matrimonio legítimo, aun con mestizas hijas de conquistadores, a fin de fundar linajes en cuya perduración se inscribía el habitus, que replicaba las jerarquías y valores sociales en una unión entre iguales (Bourdieu, 1977: 73; 1979: 189-197; 1980: 52-65; Chacón Jiménez y Martínez López, 1990: 33-35; Bestard Camps, 1992; Comas d'Argemir, 1992; Presta, 2000a: 35-38). 
Algunos linajes encomenderos fueron notablemente prolíficos y, para desvelo de patrimonios recién ensamblados que buscaban consolidar, partirlo en dotes para garantizar el mejor matrimonio para su descendencia femenina hubiera significado su ruina en una generación (Sánchez Lora, 1988: 140-141; Vigil, 1994: 208-209). De no casarse en el siglo, las doncellas tampoco podían permanecer en el hogar familiar y, vocaciones mediante, sinceras, inducidas o forzadas, podían acceder a otro matrimonio, en tanto el patriarca recurría a un esposo ideal que era el único exponente de otro mercado matrimonial, cuyos representantes terrenales requerían menores aportes dotales para el desposorio. A cambio, las doncellas que se convertían en esposas de Cristo debían honrar la castidad, probar legitimidad de origen, mostrar genealogía y prestigio social a la vez que compartir su amor y devoción junto a otras en el claustro, ámbito corporativo en el que se mantenía el orden social y los valores establecidos (Vigil, 1994: 217; Burns, 1999: 33, 146; Lavrin, 2008: 18-22). Más allá de la distancia y compromisos del matrimonio profano y el sagrado, ambos soldaban a una familia con otra, en este caso la conventual (Burns, 1999: 6) que, en ocasiones, se habían ensamblado previamente tras los vínculos de paisanaje, en los negocios compartidos y, finalmente, cristalizado en la fundación y sociabilidad del convento (Presta, 2019: 19-20). El encomendero vallisoletano Diego de Zárate, hermano del cronista y polifacético licenciado Polo Ondegardo, que había procreado diez hijos, entre ellos seis mujeres, se constituyó en la cabeza visible del grupo fundador y, merced a su posición y contactos con la burocracia local y virreinal, obtuvo el permiso necesario para fundar el monasterio, habiendo negociado con sus pares el ingreso alternativo de tres, y hasta cuatro de sus hijas, si alguna falleciera 4 .

Zárate y los padres fundadores disfrazaron sus reales propósitos de colocar a las propias hijas en el claustro bajo el argumento de ofrecer solaz y refugio a las huérfanas hijas de conquistadores, que debido al fallecimiento de sus padres vivían en pobreza y necesidad, condición que difícilmente les permitiría casarse en el siglo con el candidato que parangonara su estatus. Si entonces se decía que una doncella vivía en pobreza significaba que estaba en peligro, de allí el remedio o auxilio que podía proveer el convento para que pudiera sobrevivir y relacionarse en un espacio digno de su calidad. El peligro, dentro del imaginario patriarcal de entonces, equivalía a la exposición y el riesgo que corrían las doncellas sin amparo masculino ni recursos económicos, situación que las enfrentaba a la segura pérdida de su honra, ya que no tenían otra alternativa que sucumbir frente a hombres que robarían su honor a expensas de mantenerlas. Al no poder matrimoniarse por la carencia de una dote acorde su estatus, solo cabía depositarlas - en el leguaje de la época, sinónimo de confinarlas o colocarlas - en un convento, desposándolas con Cristo, el más adecuado de los candidatos a los que podían aspirar.

Para entonces, también era común que alguno de los hijos de las familias de la elite profesara en un monasterio y, de hecho, había varios conventos masculinos en La Plata, dado que a lo largo del siglo XVI se habían asentado los dominicos, mercedarios, agustinos, jesuitas, franciscanos y predicadores. Sin embargo, el enclaustramiento era un instituto de género, pues solo se les imponía 
a las mujeres (Sánchez Lora, 1988: 149; Lavrin, 2008: 8). El confinamiento en el claustro de modo alguno garantizaba la exención de la autoridad masculina y la liberación de las inequidades de género. Cualquiera fuera su condición, como lo observaremos a continuación, las mujeres estaban legalmente subordinadas a sus parientes masculinos, sobre todo a sus padres y maridos, pero también a sus tutores, curadores, hermanos e hijos, quienes reproducían los fundamentos patriarcales de la sociedad, que las mismas monjas asumían y, salvo excepciones, naturalizaban, para decidir sus ingresos al claustro. Aunque la vida fuera del hogar familiar pudiese favorecer un control masculino menos denso, la ideología de género y el patriarcalismo no desaparecían por la distancia familiar ni los ámbitos de convivencia de género, donde las monjas actuaban en dependencia de los mandatos de sus varones, aunque gozaran de cierta libertad que abrían hendijas para desplegar sus agencias, plantear sus necesidades y apelar a la ley que, como menores, veían restringida para hacerse oír, y hasta manipular las decisiones de otros.

Dentro de la comunidad de Los Remedios, las prácticas y voces de algunas monjas nos ilustran su deseo de profesar incentivadas por sus mayores, mientras que otras consintieron el mandato masculino para ingresar. Por otro lado, nos consta que algunas desafiaron el confinamiento y otras tantas, decididas a forjar otras vidas aún en el claustro, rompieron los votos de castidad, pobreza, reclusión y obediencia inscriptas en las reglas de Los Remedios, y de todo cenobio femenino (Presta, 2020). Si bien lo normativo, la adhesión a las reglas y su cumplimiento, explica el silencio de las actrices sociales frente a sus sinceras vocaciones, otras voces, a veces desesperadas, nos imponen la fortaleza de la voluntad masculina para que sus hijas, hermanas o esposas tomaran los hábitos, a pesar de su inexpresiva sumisión o la negativa en consentirlo. Algunas ingresaron furtivamente al convento, situación que contrastaba con la formalidad del acto de incorporación al cenobio en que la aspirante, acompañada generalmente por sus padres, era recibida por la priora y monjas profesas para dar lugar a su aceptación y acordar en capítulo las condiciones económicas del entero de dote y manutención, a fin de convertirse en novicia primero y en profesa después. Si bien tanto el ingreso programado como el furtivo garantizaban la crianza y la educación de las doncellas en el claustro (Burns, 1999: 3), asocio al último a la transgresión sexual con estado público y a otros delitos graves cometidos por mujeres cuyas familias recurrían al convento como otro espacio de refugio, aquel infranqueable que permitía sortear los rigores de la justicia y evitar la segura condena civil que por su posición de elite las familias se encargaban de enmascarar, silenciary guardar en la exclusividad del claustro (Presta 2000b; 2020). Estas disímiles situaciones de ingreso seguramente resultaron en una desafinada y compleja convivencia, lo cual invita a reflexionar acerca de la complejidad de la vida comunitaria de mujeres en reclusión que individualmente presentaban distinta situación legal y canónica, diferentes posiciones económicas, origen familiar y formación religiosa (Vigil, 1994: 215-217; Campos, 2011: 1218).

Anunciaba que en esta oportunidad trato los desafíos a las vocaciones religiosas para incursionar en los ingresos no deseados e individual 
o familiarmente disfrazados, cuyas causales radicaban en las decisiones ligadas a los imperativos patriarcales que, en representación de las necesidades familiares y la sumisión de las doncellas, concretaban la incorporación en el claustro de Los Remedios de jóvenes a quienes rara vez se había consultado sobre su disposición de ser religiosas (Reder Gadow, 2000: 284). Más allá de la libre voluntad del ingreso a un cenobio estipulada por los capítulos tridentinos, lo que conducía a la profesión era el mandato masculino de padres, hermanos y hasta maridos, cuando el matrimonio resultaba en una convivencia insoportable y el depósito de la esposa en el convento proveía de solaz para ambos o, al menos, para uno de los cónyuges (López de Ayala, 1798, II: 374-376; Sánchez Lora, 1988: 144-145; Viforcos Marinas, 1995: 523-524) ${ }^{5}$. De igual modo, el pater familias decidía a cuantas de sus hijas casaría en el siglo en función de sus disponibilidades de manutención y, sobre todo, para conservar su patrimonio indiviso y estabilizado evitando la erogación de abultadas dotes acordes a la jerarquía de las doncellas y su candidato. Selección mediante, que marcaba la planificación interna y las diferencias arbitrarias dentro de la familia, una o más hijas ingresarían al convento, donde las dotes eran menos onerosas y evitaban la licuación del capital económico, aunque preservando e incrementando el simbólico y social que enlazaban a parientes y allegados en el prestigio de formar parte de una institución de conocida reputación donde otras redes y relaciones se incrementaban y renovaban entre pares. De manera que el patriarcado, vertebrador de la ideología de género que imperaba en la sociedad y que hacían propia las mismas monjas, estaba instalado en el claustro y no solamente obedecía a la presencia de las autoridades y profesionales masculinos que lo visitaban (cf. Lavrin, 2008: 9; Gómez Navarro, 2011: 206), sino a la manera de asumir las prácticas y representaciones, obediencia y naturalizaciones de género de mujeres que utilizaban resquicios y oportunidades para filtrar sus agencias. De manera que el presente ensayo, por su temática y perspectiva de análisis, resulta una propuesta original frente a las numerosas investigaciones que sobre las mujeres en reclusión han proliferado en los estudios coloniales hispanoamericanos en las últimas décadas. El supuesto ideario monástico de voluntaria y equilibrada convivencia en la clausura se contradice tras las voces recuperadas de algunas monjas de Los Remedios, las que invitan a revisar las trayectorias individuales de novicias y profesas tras las impactantes confesiones de instancias de vida y sentimientos que aparecen en los protocolos notariales procedentes del repositorio mayor boliviano que presento a continuación y que abonan al propósito de esta exposición.

\section{Los tres matrimonios de doña Francisca de Alvarado}

En la primavera de 1602, el secretario de la Real Audiencia, Juan de Losa Barahona, se presentaba en Los Remedios junto a doña Francisca de Alvarado-hija legítima del encomendero capitán Cristóbal Barba de Alvarado y de Ana de Olmos, difuntos- a quien decía apoyar financieramente en su decisión de profesar. El Secretario se obligaba a pagar a la priora, comunidad de monjas y su mayordomo 2000 pesos ensayados en concepto de dote, si la aspirante profesara al año del ingreso. De no hacerlo, la donación sería revocada. En 
el entretanto, doña Francisca recibía el hábito de religiosa ${ }^{6}$. Acercándose la fecha de tomar los votos, doña Francisca hizo llamar a un notario. Detrás de las rejas del coro que la separaban del escribano y los tres necesarios testigos, doña Francisca se identificaba como la legítima esposa de Pedro González Picón, vecino de La Plata y a la sazón tras la reja, y decía haber sido calumniosamente acusada por su marido ante la Real Audiencia de La Plata por haber cometido cierto delito que no explicitaba, tras lo cual se la había condenado a muerte en rebeldía, una vez refugiada en Los Remedios. Asumiéndose inocente y debido a esa condena, en sus palabras, "sola y desamparada en su fragilidad", doña Francisca se había refugiado en el convento a fin de preservarse de las amenazas públicas sumadas a la persuasión y el amedrentamiento que su marido hacía a potenciales testigos para separarla de sus hijos e impedirle el acceso a sus bienes dotales y demás propiedades. Valga recordar que la mujer era entonces considerada menor de edad, como los niños y los indígenas, necesitando siempre de la tutela o curaduría de un varón para presentarse ante notario, administrar sus bienes o formalizar toda clase de contratos, salvo que tuviera licencia de marido, padre, curador, alcalde ordinario de la jurisdicción o priora del convento. Atadas a la figura jurídica del imbecillitas sexus, la inferioridad femenina constituía un instituto maleable, toda vez que la mujer buscara ampararse en esa norma, trascender su "fragilidad" o falta de entendimiento y responsabilidad frente a cualquier hecho o delito (Borchart de Moreno, 1991; Presta, 2000b: 241).
Más allá de la estrategia precedente, que aparentemente mostraba a la novicia sometida a su condición jurídica, doña Francisca declaraba que el claustro no le había provisto ni abrigo ni tranquilidad sino el rechazo de una comunidad temerosa del poder de su marido y, quizás, la discriminación por el inconfesado delito. Abandonada y en soledad, había resuelto no profesar dado que carecía de vocación, haciendo exclamación todas las veces que el derecho le permitiera, para explicitar que nada haría contra su voluntad7. Más allá de la hostilidad de sus pares, es notorio que doña Francisca ni tenía vocación ni, por ende, se habría adaptado a la soledad de su celda, las actividades comunes y los horarios y secuencias de rezos y, menos aún, a la clausura, verdadera cárcel para quien distaba de apreciar y buscar la perfección espiritual, la virtud y la libertad en el encierro. En suma, la novicia distaba de haber aprendido a vivir en comunidad, en el desarraigo de lo material y en las barreras impuestas a la vida social, que imponían un "deber ser" que no estaba entre las decisiones de la futura profesa (Gómez Navarro, 2018: 122-123, 135). Es más, aunque admitida como casada, las condiciones de refugio para una mujer casada eran excepcionales y solo plausibles si peligrara la vida, tal como ocurría con doña Francisca (Arbiol, 1717, XXXIII: 195-198).

Un año más tarde y a casi tres de vivir en Los Remedios, doña Francisca nos ofrece, en otra escritura pública formalizada frente al notario y testigos, su filiación completa y sintético derrotero de vida. Declaraba sus vínculos familiares y decía haberse casado legítimamente con Pedro González Picón, con quien había procreado cuatro hijos: Pedro, Francisco, Juan y Cristobalina, quienes 
por entonces tenían entre 16 y 9 años. Que además de llevar en dote una casa de morada y otros bienes y recibido arras de su esposo, al ingresar al convento, el Secretario Losa Barahona le había entregado 969 pesos corrientes en efectivo y ajuar para su manutención y vestido, todo lo cual se detalla en un Anexo. Asimismo, su benefactor le había prometido otros mil pesos ensayados a más de todo lo necesario para profesar, mientras ella renunciaba a su dote y gananciales en favor de sus hijos ${ }^{8}$. Habían pasado casi tres años y doña Francisca, ingresada y en hábitos de religiosa, habiendo renunciado a sus bienes en el siglo y manifestando su voluntad, finalmente, de permanecer en Los Remedios, aún no había tomado los votos ni hecho profesión.

Dos años más tarde, doña Francisca vuelve a hablar; ante prelados y autoridades de Los Remedios manifiesta su voluntad de profesar y legar, definitivamente, la totalidad de sus bienes en su marido, hijos, herederos y sucesores; en sus palabras: "como si fuera fallecida... pues en cuanto al siglo y habiendo hecho la dicha profesión me hago muerta"9. Pasados dos años de la toma de votos, en 1607 falleció Pedro González Picón, quien fuera marido en el siglo de la monja profesa. Casi de inmediato, doña Francisca interpuso un recurso de nulidad sobre su profesión forzada ante el juzgado eclesiástico de la ciudad de La Plata, nombrando procuradores para proseguir el pleito que se presentaría en su nombre ante el cabildo de la Santa Iglesia Catedral de esa ciudad, donde se trataban esas materias. Al mismo tiempo, daba poderes para recuperar sus bienes, aun los vendidos, rematados y enajenados ${ }^{10}$. Dos veces casada y viuda en el siglo, después de su matrimonio sagrado, doña Francisca quería prescindir, tras las idas y vueltas de una profesión claramente inducida y no deseada, de su marido espiritual. ¿Era factible divorciarse de Dios? ¿Cómo leer su solicitud de abandonar el claustro debido a un ingreso conflictivo que derivó en una profesión no querida? ¿Había colisión entre una petición legítima y el aparato legal que la recibía, luego de la profesión y los votos contraídos? ¿De qué manera la familia de doña Francisca y la elite a la que pertenecía estaban preparadas para el regreso social de una supuesta exconvicta y monja al lugar en que siempre quiso estar? Lo cierto es que, a cinco años de la petición de nulidad de los votos, doña Francisca reaparece en los protocolos notariales casada con un tal Luis Guerra de Salazar, a quien daba poder para cobrar de los herederos y albaceas de su primer marido la dote y arras que había recibido al tiempo del matrimonio, como también solicitaba la partición y división de bienes con los demás coherederos ${ }^{11}$.

Doña Francisca debió haber sido muy joven al casarse en primeras nupcias y reiterar su estado nupcial dos veces más, pues en 1640 ya era viuda de su tercer marido, Luis Guerra Salazar, al reclamar el cobro de deudas pendientes ${ }^{12}$. Testó en La Plata en 1644 y su rastro se pierde tras ese último protocolo que, por trunco y deteriorado, es difícil de recuperar para esta investigación ${ }^{13}$. No obstante ello, el itinerario civil de doña Francisca de Alvarado, su enclaustramiento de casi una década y su retorno al siglo, dan cuenta de las incontrastables prácticas y estrategias masculinas que no trepidaron, para lograr sus fines de separación vincular y reclusión, lesionar el honor de una esposa y enajenar su voluntad. Sin 
dudas, doña Francisca profesó sin vocación para salvar su vida, aunque la viudez y la forzada toma de votos le abrieron el camino para desandar el enclaustramiento, las donaciones y renuncias patrimoniales, para alcanzar un definitivo retorno al siglo en el que tuvo una tercera oportunidad matrimonial.

\section{Tres hermanasy una misma y sugerida vocación}

En marzo de 1610, luego de que sus padres, el comerciante extremeño Juan Ramírez Téllez y doña Luisa de Haro, hija "natural" dellicenciado Antonio López de Haro, oidor que fuera de la primera Audiencia de Charcas fallecieran, tres hermanas adolescentes eran admitidas en Los Remedios para proseguir su noviciado hasta profesar al año del ingreso ${ }^{14}$. Doña Fabiana y doña Luisa de Haro y doña Ana de Espinosa habían sellado ese compromiso frente a la abadesa, la comunidad de monjas y su hermano mayor, Juan Ramírez Téllez, a la vez su tutor y curador, quien se comprometió a integrar por cada una 2000 pesos ensayados al momento de la profesión más 300 pesos de igual moneda en concepto de mantenimiento y ajuar ${ }^{15}$. A tres años del ingreso, y largamente cumplido el año de aprobación, las tres novicias decían esperar que su hermano cumpliese con el pago de las dotes para profesar y, más allá del respeto que le tenían, con el mayor pedimento y persuasión después de haber renunciado a sus legítimas de padre y madre sin haber recibido manutención ni dotes, bajo la figura de la exclamación, las tres declaraban haber sido forzadas y urgidas para entrar al convento contra su voluntad, protestando sobre la renunciación y donación de sus herencias, todo lo cual daban por inválido ${ }^{16}$. Con seguridad, las dificultades financieras de Juan Ramírez Téllez prosiguieron a lo largo de la década, siendo recién en 1618 cuando la comunidad de monjas hacía lugar a la profesión de doña Ana de Espinosa, aunque la dote de 2000 pesos no había sido completada, concediendo al curador un año de plazo para el pago total y el entero de los alimentos de su hermana. En el mismo acto de compromiso de profesión y reclamo de la dote, la novicia legaba todos sus bienes a su hermano, al sentirse en "mucha obligación" por el remedio efectuado para la toma de sus votos ${ }^{17}$.

Curiosamente, en 1593 los padres de las hermanas Haro se habían constituido, y sus herederos lo continuaban siendo, en censatarios de la dote de la mestiza monja profesa María de la Trinidad, cuyo monto de 1400 pesos corrientes y 800 ensayados habían impuesto sobre sus casas de morada en la ciudad. Ese vínculo quedaba asimismo reforzado por el testamento del presbítero Francisco Sevillano, padre "natural" de María, quien efectuaba donaciones a la madre de las futuras monjas y a su hermana menor, para su remedio y casamiento ${ }^{18}$. Desde 1596, María de la Trinidad, junto a la priora de los Remedios, reclamaba los corridos impagos de ese censo, llegando a solicitar el remate de los inmuebles, mientras otorgaba poder general para la cobranza de sus deudas, denotando la iliquidez de los padres de las profesas Haro Espinosa que, más tarde, heredara su hijo mayor y curador de sus hermanas quien, durante una década debió negociar y refinanciar las deudas contraídas con el convento y la comunidad de sus monjas ${ }^{19}$. Estos últimos vínculos no solo resultaban financieros, sino que denotaban la amistad entre las familias de monjas cuyas diferencias de estatus y económicas 
se habrían entreacortadoy profundizado, mientras la cercanía entre las profesas pudo haber sufrido ciertos altibajos debido a las deudas impagas del hermano de las Haro Espinosa, que recortaban los gastos y la misma alimentación de María de la Trinidad. Situaciones como esta denotaban que otros intereses, más allá de los religiosos, anidaban en el claustro y proveían a la desconfianza, distancia y resentimiento entre quienes compartían la vida en la ilusión de ser hermanas.

\section{Montaje e ingreso furtivo de la musa inspira- dora de un crimen}

Pero si un caso paradigmático de profesión forzada y furtiva en Los Remedios he develado fue el de doña Jerónima de Zárate, hija del fundador y primer patrón del convento. Cuando hallé los primeros indicios de las causas que motivaron aquel ingreso (Presta, 2000b: 244-247), no estaba inmersa en la temática conventual ni poseía el acervo adecuado para encarar su hermenéutica desde los varios flancos que concurren en el ingreso furtivo de una hija de la elite, hasta entonces casada y madre de una hija pequeña. Como se advirtiera, el matrimonio del encomendero Diego de Zárate Ondegardo y doña Catalina de Zurbarán había procreado seis hijas mujeres entre diez hijos criados en un ámbito de "inflación de honores" (Stone, 1965: 65-128), atribuible a un hogar que aspiraba a constituirse en linaje tras las rentas de una encomienda diversificada en negocios agrícola-ganaderos y mineros en el sur andino. Aunque prestigiosa, la vecindad, acompañada por una estrecha red relacional nutrida de parientes y pares, no se equiparaba a un patrimonio reciente que podía esfumarse si los Zárate-Zurbarán casaran a toda su prole femenina (Presta, 2000b: 245; Presta, 2019: 19). La imposibilidad de mantener acorde a su jerarquía a las seis hijas en el hogar familiar, donde desde la vestimenta a la participación social hacían a la visibilidad pública en coordinación con la vida privada, derivó en que Zárate utilizara la prebenda acordada con los demás fundadores para comenzar a ingresar sus hijas en Los Remedios. Luego de la viudez y hasta sus segundas nupcias, ingresó doña María y otras dos de sus hijas se alternaron en el claustro, sin tomar los votos (Presta, 2019: 21).

Interesa a esta propuesta el ingreso furtivo de doña Jerónima de Zárate, quien desde 1582 estaba casada con Alonso Tufiño, minero de Potosí, asiento en el que los esposos habían fijado residencia. Tufino había recibido 5000 pesos ensayados en dote y había entregado igual suma en arras nupciales ${ }^{20}$. Más allá de la inicial y corta obediencia al mandato patriarcal, doña Jerónima, que mantenía una activa vida social, no tardó en trabar una relación amorosa con el hijo del corregidor de Potosí, don Alonso Ortiz de Leiva, quien durante meses la rodeó con un cortejo fascinante y cegador del que se hicieron cómplices amigos comunes y del que fueron eco los cronistas Calancha ([1639] 1976, III: 1183-1185) y Arzans de Orsúa y Vela ([1735] 1965, I: 290-292) aunque describieron con nombres cambiados y sensibles alteraciones los hechos por venir (Presta, 2000b: 246; Presta, 2019: 21). Los avances de Leiva chocaron con reiteradas negativas y desplantes. Agobiado por tanto rechazo, tomó distancia y, con ello, despertó el interés de doña Jerónima. De allí en más, se convirtieron en amantes. Su situación se hizo insostenible y, para vivir su relación en 
libertad, planificaron el asesinato de Tufiño. Una noche de enero de 1586, mientras caminaba hacia su casa, tres sicarios contratados por los amantes lo apuñalaron en las calles de Potosí. Tufiño no murió de inmediato. Vivió un par de semanas como para contar al oidor licenciado Lopidana, enviado de la Audiencia de Charcas, los avatares sufridos y la identidad de sus atacantes. El oidor llegó a interrogar a Leiva en el Cabildo de Potosí al saber que días antes del ataque a Tufiño ambos habían intercambiado palabras en la plaza pública y que el moribundo lo había citado como parte de la emboscada. Aunque se le había dado el Cabildo como cárcel y se lo había interrogado en varias ocasiones, a mediados de marzo de 1586 Leiva se fugó para reaparecer en Sevilla y más tarde en Madrid, para en 1595 ser indultado por el virrey don García Hurtado de Mendoza21.

Luego de un interrogatorio inicial, doña Jerónima presentó querella en su nombre y el de su hija menor por lo que nombraba el "alevoso delito cometido en la persona de mi esposo". Interrogados numerosos testigos españoles, mitayos y esclavos, el oidor Lopidana mandó prender a doña Jerónima dándole por cárcel la casa del tesorero Diego Bravo y su esposa, fianza mediante, hasta que la fuga de su amante precipitó el devenir de los acontecimientos. Nuevamente interrogada, doña Jerónima incurrió en contradicciones que llevaron a los oidores a darle cárcel en casa de su madre en La Plata e, inseguros de tal decisión, la confinan en casa del alcalde ordinario, a la que no llegó debido a un notable montaje armado por su familia, parientes y amigos, que tramitaban silenciosamente su fuga, exhibiendo la prolongación de las redes relacionales en la solidaridad corporativa de la nombrada "familia religiosa" (Gómez Navarro, 2018: 120). Cuando los funcionarios arribaron a casa de los Zárate OndegardoZurbarán, doña María, hermana mayor de la inculpada, estaba vestida de luto y con la cara tapada por tal condición simulando ser doña Jerónima. Mientras la falsa rea se encaminaba a la cárcel, su hermana ingresaba junto a su madre y otras damas honorables al Monasterio de los Remedios, donde profesó de inmediato. Con el correr de los años, articulando densas redes externas e internas, doña Jerónima, a más de administrar sus bienes, citar a su hermano mayor y efectuar transacciones comerciales, se convirtió en superiora, priora y maestra de novicias ${ }^{22}$.

Visto este evento con ojos y categorías contemporáneos, y solo teniendo en cuenta el adulterio de doña Jerónima, se podría colegir que la devenida en monja fue una transgresora. Adicionalmente, si sumamos a la transgresión la programación del asesinato del esposo, el encubrimiento del amante y su propia responsabilidad en los hechos, daríamos cuenta de una criminal apañada por su familia, la gran familia extendida que constituía la elite y, finalmente, la corporación convento que, al ingresar furtivamente, la había aceptado de inmediato y contribuido al propósito de eludir la justicia. El análisis de un caso de ingreso furtivo, con los agregados del montaje y el engaño, debe situarse en contextoy proveer a una ajustada hermenéutica en espacio y tiempo. Inicialmente, convengamos que la conducta pública de doña Jerónima de Zárate no era la esperada de una mujer de la elite, casada y madre de familia pues, si de relaciones ilícitas se tratara, el comportamiento ideal era mantenerlas en la esfera privada y dentro de un 
saludable y aceptado disimulo, práctica propia de las elites y menos condenable que la mentira (Hespanha, 1994-1995: 65; 1998: 62).

Por otro lado, el crimen y el escándalo, a más de inaceptables, eran patrimonio de los de abajo, aquellos a quienes tanto la sociedad jerárquica peninsular como la colonial consideraban viles, carentes de honor, honestidad y demás valores que patrimonializaban las elites. La sociedad de órdenes gozaba de un equilibrio jerárquico y vincular de las personas, que asumían y desarrollaban prácticas de acuerdo a su estado. Conforme a ello, la justicia distaba de ser la misma para cada corporación o estado dentro de la sociedad estamental. Los cabeza de familia eran responsables de la prosperidad y gobierno de sus casas $\mathrm{y}$, sobre todo, de ejercer la autoridad y cuidar la honra de sus mujeres, que por su condición de género estaban sujetas a permanente tutela y, tras ella, podían sortear los rigores y supervisión de la justicia. Si además enmarcamos esta ideología junto a la cultura del simulacro o disimulo, que se caracterizaba por soslayar las iniquidades y aún las faltas graves morigerándolas y tiñéndolas con el embuste y el engaño, resulta factible comprender no solo el comportamiento de doña Jerónima y el de su familia, sino también su crecimiento en cargos de poder y estatus dentro de la corporación conventual (Clavero, 2006: 8-9; Hespanha, 1998: 61-62). Si entendemos al convento como "un invernadero en flor exclusivamente abierto para aquellas de impecable pedigrí" (Lavrin, 2008: 5), doña Jerónima era una excelsa representante de la elite charqueña e hija del primer patrón y fundador $\mathrm{y}$, por ello, sus faltas gravísimas, un equívoco disimulable y olvidable en el imaginario de entonces.

\section{Conclusiones}

Los Remedios, como monasterio de monjas creado por un conjunto de padres de familia cuya función era sostener el sistema y proveer al equilibrio social, fue la prolongación de sus casas pobladas, el espacio sagrado cercano a las residencias profanas en que el guardaron y supervisaron a sus hijas monjas, ingresadas con vocación o sin ella.

Las motivaciones que llevaron a las doncellas, solteras o casadas, a profesar fueron variadas, más allá de que la legislación de Trento solo favoreciera la vocación real y el libre albedrío de las involucradas, excluyendo y penalizando con la excomunión a todo aquel que forzara o violentara la voluntad de una mujer para inducirla a la vida religiosa.

Los ingresos narrados en esta investigación dan cuenta de la fortaleza del patriarcado y la ideología que lo sustentaba, inmersa en la inferioridad femenina y sostenida en la responsabilidad masculina de salvaguardar el honor familiar tras la protección de la honra de sus mujeres, cuya materialización no era otra que el enclaustramiento. Esa ideología abarcaba al cuerpo social y la asumían y reproducían las mujeres que consentían, como doña Francisca de Alvarado y las hermanas Haro Espinosa, sus ingresos forzados, aunque fundados en causales diferentes. Más allá del supuesto crimen de doña Francisca y los ingresos de las tres adolescentes, lo cierto es que las cuatro cumplieron, hasta cierto punto, con el mandato del marido y el hermano mayor, sin rehusarse, inicialmente, al confinamiento de por vida. 
Doña Francisca, presa de acusaciones aparentemente judiciables pero también de una determinación por vivir fuera del enclaustramiento, alzó su voz en varias ocasiones para desgranar, secuencialmente, las razones de su depósito. Las numerosas instancias en que se comunicó con el siglo para solicitar la presencia de un escribano y testigos, movilizando tanto a las autoridades del convento como a sus custodios espirituales, dan cuenta de la dilación en profesar fundada en su falta de vocación junto a una decisión tomada por circunstancias inconfesas que motivaron la presión de su marido y allegados, como el mismo Secretario de la Real Audiencia que financió, quizás con dinero del cónyuge, su ingreso y manutención. Aunque profesó, llegada la ocasión de su viudez en el siglo, no esperó un instante para nulificar sus votos y abandonar el monasterio con la venia del cabildo eclesiástico de la Iglesia Catedral de La Plata. Recibió un halo de luz al enviudar de su marido y padre de sus hijos a dos años de haber profesado. Los capítulos tridentinos establecían que si fuera probado dentro de los cinco años de la profesión que la misma había ocurrido por presión externa, violencia o inducimiento, la monja estaba en su derecho a solicitar la nulidad de los votos. La profesión de doña Francisca arraigaba en la legislación, aunque no habrán sido pocas las dificultades para volver al siglo e intentar recuperar su vida social, lo cual consiguió al acceder a un segundo matrimonio profano, condición que agilizaba el ansiado retorno a la vida deseada (Vigil, 1994: 209-210). Sostenerse en un esposo le daba la posibilidad de demandar judicialmente la devolución de sus bienes legados en circunstancias opresivas. El nuevo marido habrá hecho lo propio, máxime cuando de la recuperación de los bienes de su esposa se garantizaba el entero de la dote seguramente prometida. Doña Francisca de Alvarado fue, quizás, una de las pocas mujeres charqueñas que tuvo tres maridos, dos en el siglo y uno en el claustro, del cual decidió separarse para recuperar su autonomía y vida social en el mundo que nunca deseó abandonar.

Sumisas, jóvenes y aparentemente resignadas, las hermanas Haro-Espinosa se entregaron al noviciado una vez fallecidos sus padres $y$, por lo expuesto, incentivadas por su hermano mayor, devenido en patriarca de la familia. Aunque variadas, las formas de ingreso de niñas y adolescentes a los conventos trascendían la salvaguarda de su honra y anclaban en motivos económicos (Sanz de Bremond y Mayáns, 2000: 406-408). Es notable el ingreso de las tres hijas mujeres al claustro, sin considerar la posibilidad de un matrimonio en el siglo para, al menos, una de ellas. La endeble situación económica familiar, las deudas que dejaran los padres y la imposibilidad de erogarlas, derivó en la decisión del nuevo cabeza de familia en depositar a sus hermanas en Los Remedios. Seguramente, la falta de equilibrio entre el capital y el prestigio necesarios para casar, al menos, a una de sus hermanas con un candidato adecuado en honor y patrimonio, habrá incidido crucialmente en el ingreso de las tres, de allí que los conventos fueran un refugio para mujeres de calidad cuyas familias estaban imposibilitadas de erogar las excesivas dotes que equipararan su condición social con la fortuna familiar (Sánchez Lora, 1988: 139-142).

Así, doña Fabiana y doña Luisa de Haro y doña Ana de Espinosa manifestaron con su silencio el 
consentimiento a la propuesta y voluntad de su hermano mayor. Sin embargo, inspirada en la normativa tridentina, la decisión de convertirse en monja debía ser la expresión de la sincera vocación y libre elección, correspondiendo examinar si la misma venía "violentada de su parientes; porque en esto suele haber mucho peligro", (Arbiol, 1717, VII: 35). De igual modo, el fraile franciscano advertía que la admisión era de por vida, para educarse como esposas del Hijo de Dios y llegar al ideal de perfección, cuestión difícilmente considerada por las núbiles hermanas. Presumiblemente, la juventud e inocencia de doña Fabiana, doña Luisa y doña Ana habrán soslayado la profundidad del tiempo, el significado de la reclusión perpetua y los imperativos de la vida intramuros. Más allá de consentir su ingreso y cumplir con la solicitud del hermano mayor, por años reclamaron el cumplimiento del compromiso debido a su condición y supervivencia: sus dotes y manutención largamente adeudadas, deslizando, en cada exclamación, que habían sido obligadas a renunciar a sus legítimas en favor de su hermano sin haberlo deseado, con lo cual ponían en tela de juicio sus homogéneas vocaciones tras las herencias donadas contra su voluntad, aunque privilegiando la obediencia debida al patriarca de su familia.

El ingreso furtivo de doña Jerónima de Zárate por la naturaleza de su crimen, largamente publicitado en Potosí y La Plata, es una muestra más de la vitalidad de las redes de pares y el incontrastable peso de la familia fundadora, cuyo patronazgo ejerció hasta su muerte el padre de la futura superiora y maestra de novicias. La rápida profesión de doña Jerónima de Zárate Ondegardo, como se hacía llamar en el convento, exhibe la fortaleza de la sociedad estamentaly sus valores, encarnados en una mujer casada que bien pudo rifar el honor de su familia, de no mediar la férrea intervención y acompañamiento de una elite local que no podía permitirse el menor de los deslices de una de sus hijas. Si adúltera, en privado; crimen mediante y descubierta, la única salida era el convento, a fin de evitar el escarnio público del sometimiento a una justicia que no podía evitar mostrar semejante crimen: el asesinato por encargo del marido de doña Jerónima.

Justamente, los ideales del honor, la probidad, la verdad y la fidelidad mancillados por una dama casada fueron rápidamente disimulados, montaje mediante, por la corporación elite que, cerrándose en sí misma, buscó omitir, disfrazar y maquillar las prácticas indignas de una integrante notable de su estamento.

Esta última circunstancia, como las previas, exhibe de qué manera los padres fundadores y sus allegados utilizaban al convento como una suerte de franquicia de sus propias casas. El claustro fue una instancia superadora de los desvelos económicos y patrimoniales que impedían el matrimonio de sus hijas con el candidato adecuado, como también el encierro para una esposa díscola y el de otra dama casada que llegó a planificar un crimen para vivir su pasión imposible.

Los ingresos a Los Remedios recuperados en las notarías de La Plata, junto a las voces de sus actrices, ilustran las desigualdades internas visibles en el claustro. Lejos de ser un espacio ideal, donde reinaba la hermandad, la solidaridad y el proyecto común de un conjunto de mujeres supuestamente 
elegidas para convertirse en esposas de Cristo, el claustro replicaba las diferencias entre las monjas y, en la investigación que nos ocupa, las vocaciones ausentes, la centralidad de la familia y el vigor del patriarcado que hacían del convento una prolongación de las casas pobladas en que el poder del pater familias se extendía desde el ámbito profano al sagrado.

\section{Anexo}

ABNB EP 100 Agustín de Herrera - La Plata, 4.06.1604, fs. 352-357

Detalle de los 969 pesos corrientes que el Secretario Juan de Losa Barahona diera a doña Francisca de Alvarado antes de profesar, en las partidas siguientes:

$[352 \mathrm{v}]$

100 pesos ensayados que le dio para sus alimentos el año de noviciado que son corrientes 156 y 2 tomines

tres varas de cordellate en 5 pesos y 2 tomines

cuatro varas de bocací, 2 pesos 4 tomines

un mazo de cintas blancas, un pesos 2 tomines

seis docenas y media de botones de alquimia a 4 pesos 2 tomines

dos pesos de agujas

14 pesos de dos piezas de tocas de la China dos onzas de seda de la China, a tres pesos

una cuja y pabellón, una caja grande y otra pequeña [353r]

otra caja grande con su cerradura, lo mismo porque ésta y la de la partida de arriba es todo una

unos chapines 15 pesos

unos botines y pantuflillos, 6 pesos

14 varas de lienzo de Tucumán a peso y seis reales vara

una libra de hilo de acarreto para hacer dos colchones, 2 pesos

de hilera, seis reales

tres frezadas, una para el servicio y dos para ella, 30 pesos

para el sastre de la hechura de dos hábitos, dos escapularios, dos sayas, dos faldellines, dos jubones, treinta y nueve pesos

40 velas de cera de a cuarta y de a libra que todas pesaron 14 libras, 35 pesos

2 docenas de platos y escudillas de loza, 6 pesos

4 arrobas de lana para dos colchones, 8 pesos [353v] 
que pagó por ella en la tienda del capitán Francisco Jaramillo 555 pesos corrientes todo lo cual Juan de Losa le dio para sus alimentos y ajuar y pagó en la tienda del capitán Fernando Jaramillo, que eran de ropa y mercaderías que se sacaron para ella...para que ella quedara en la religión y profesase en ella y por hacer bien a sus hijos y para que les fuese cierto y seguro lo que de yuso se hará mención...

\section{Referencias citadas}

Atienza López, Á. (2010): “Nobleza, poder señorial y conventos en la España Moderna. La dimensión política de las fundaciones nobiliarias", en E. Sarana Sánchez y E. Serrano Martín coords., Estudios sobre señorío y feudalismo: homenaje a Julio Valdeón, Zaragoza, Institución Fernando el Católico, pp. 235-269.

Arancibia, G. ([1868] 1872): “Necesidad dela reducción de los tres monasterios de esta capital en dos", en Colección de documentos bolivianos recogidos y ordenados por Gabriel René Moreno. Periódicos y hojas sueltas, 1865-1869, Tomo 5, Santiago de Chile.

Arancibia, J. M. Mons. y C. O. Ponza, eds. (2014): Historia del Monasterio de Santa Catalina de Sena de la ciudad de Córdoba por religiosas del mismo monasterio, La Calera, Industria Gráfica Cervantes.

Arbiol, fray A. (1717): La Religiosa Instruida, con doctrina de la Sagrada Escritura y los Santos Padre de la Iglesia Católica. Zaragoza, Herederos de Manuel Román.

Ares Queija. B. (2004): “Mancebas de españoles, madres de mestizos. Imágenes de la mujer indígena en el Perú colonial temprano", en P. Gonzalbo Aizpuru y B.
Ares Queija coords., Las mujeres en la construcción de las sociedades iberoamericanas, Sevilla-México, Consejo Superior de Investigaciones Científicas-EEHA/El Colegio de México-CEH, pp. 16-39.

Arzans de Orsúa y Vela, B. [1735] (1965): Historia de la Villa Imperial de Potosí, L. Hanke y G. Mendoza eds., 3 Vols., Providence, RI, Brown University Press.

Berrío, D. J. (1909): “Clausura de Monasterios y Conventos”, La Paz, Tipografía La Patria de Eulojio Córdova.

Bestard Camps, J. (1992): "La estrechez del lugar. Reflexiones en torno a las estrategias matrimoniales cercanas" en F. Chacón Jiménez y J. Hernández Franco eds., Poder, familia y consanguinidad en la España del Antiguo Régimen, Barcelona, Anthropos, pp. 107-156.

Borchart de Moreno, C. (1991): “La imbecilidad y el coraje. La participación femenina en la economía colonial (Quito, 1780-1839)", Revista Complutense de Historia de América, 17, pp. 167-182.

Bourdieu, P. (1977): Outline of a Theory of Practice, Cambridge, Cambridge University Press.

Bourdieu, P. (1979): La distinction: critique sociale du jugement, París, Les Editions du Minuit.

Bourdieu, P. (1980): The Logic of Practice, Stanford, Stanford University Press.

Braccio, G. (1999): "Para mejor servir a Dios. El oficio de ser monja”, en F. Devoto y M. Madero comps., Historia de la vida privada en la argentina, tomo I, País Antiguo, De la Colonia a 1870, Buenos Aires, Taurus, pp. 225-249. 
Braccio, G. (2000): “Una ventana hacia otro mundo, Santa Catalina de Sena: primer convento femenino de Buenos Aires", Colonial Latin American Review, 9 (2), pp.187-212.

Burns, K. (1999): Colonial Habits. Convents and the Spiritual Economy of Cuzco, Peru, Durham, Duke University Press.

Burns, K. (2007): “Unfixing Race”, en M. R. Greer, W. D. Mignolo and M. Quilligan eds., Rereading the Black Legend. The Discourses about Religious and Racial Difference in the Renaissance Empires, Chicago, University of Chicago Press, pp. 188-202.

Campos y Fernández de Sevilla, F. J. (2011): “Monacato femenino y recolección. Ntra. Sra. del Prado de Lima: fidelidad y crisis del setecientos (1650-1800)", en Actas del Simposio La Clausura Femenina en el Mundo Hispánico. Una Fidelidad Secular, San Lorenzo del Escorial 2-5 de septiembre, Vol. 2, pp. 1209-1248.

Calancha, fray A. de la [1639] (1974-1982): Crónica Moralizada del Orden de San Agustín en el Perú. Ignacio Prado Pastor ed., 6 Tomos, Lima, Universidad Mayor de San Marcos.

Chacón Jiménez, F. y J. Martínez López (1990): “La historia de la familia en España durante la Edad Moderna. Notas para una reflexión metodológica”, en F. Chacón Jiménez ed., Historia Social de la Familia en España. Aproximación a los problemas de familia, tierra y sociedad en Castilla (ss. XV-XIX), Alicante, Instituto de Cultura Juan Gil Albert, pp. 31-44.

Clavero, B. (2006): “Justicia y Gobierno, Economía y Gracia”, en J. Moya Morales, E. Quesada Dorador y
D. Torres Ibáñez eds., Real Chancillería de Granada: V Centenario (1505-2005), Granada, Junta de Andalucía, pp. 1-13.

Cohen Imach, V. (2003): "Decir verdad. Pesquisa secreta en un convento femenino (sigo XVIII)", Acta Literaria, 28, pp. 37-48.

Cohen Imach, V. (2006): “Esposas de Cristo ante el visitador. Interrogatorios en el convento de Santa Catalina de Siena (Córdoba, siglo XVIII)", Telar, 4, pp. 40-54.

Comas d'Argemir, M. D. (1992): “Matrimonio, patrimonio y descendencia. Algunas hipótesis referidas a la Península Ibérica”, en F. Chacón Jiménez y J. Hernández Franco eds., Poder, familia y consanguinidad en la España del Antiguo Régimen, Barcelona, Anthropos, pp. 157-175.

Fraschina, A. (1999): “Despreciando el mundo y sus vanidades. Los conventos de monjas en el Buenos Aires colonial", Cuadernos de Historia Regional, 20-21, pp. 71-101.

Fraschina, A. (2000): "La clausura monacal: hierofanía y espejo de la sociedad", Andes, 11, pp. 209-236.

Fraschina, A. (2010): Mujeres Consagradas en el Buenos Aires Colonial, Buenos Aires, EUDEBA.

García Quintanilla, J. Mons. (1963): Historia de la Iglesia de los Charcas o La Plata (Sucre Bolivia), Tomo III, Sucre, Talleres Gráficos Don Bosco.

Gómez Navarro, M. S. (2011): “De rejas adentro: monjas y religiosas en la España moderna. Una historia 
de diferencias en la igualdad", Revista de Historia Moderna, 29, pp. 205-227.

Gómez Navarro, M. S. (2018): "La familia religiosa en la España Moderna: balance y propuesta analítica”. Historia Social, 92, pp. 119-138.

Hering Torres, M. S. (2011a): “La limpieza de sangre. Problemas de interpretación: acercamientos históricos y metodológicos", Historia Crítica, 45, pp. 32-55.

Hering Torres, M. S. (2011b): “La Limpieza de Sangre en España: un modelo de interpretación", en N. Böttcher, B. Hausberger y M. S. Hering Torres, coords. El peso de la sangre. Limpios, Mestizos y Nobles en el Mundo Hispánico, México, El Colegio de México, pp. 23-54.

Hespanha, A. M. (1994-1995): “Las categorías de lo político y de lo jurídico en la época moderna”. Revista Interdisciplinar de Estudios Histórico-jurídicos, 3-4, pp. 63-100.

Hespanha, A. M. (1998): Cultura Jurídica europea. Síntesis de un milenio, Tecnos, Madrid.

Lavrin, A. (1973): "La riqueza de los conventos de monjas en Nueva España: estructura y evolución en el siglo XVIII)", Cahiers des Amériques Latines, 53, pp. 27-49.

Lavrin, A. (1975): "El convento de Santa Clara de Querétaro: la administración de sus propiedades en el siglo XVII", Historia Mexicana, 97, pp. 76-117.

Lavrin, A. (2008): Brides of Christ. Conventual Life in Colonial Mexico, Stanford, Stanford University Press.

López Hernández, J. (2005): Introducción Histórica a la Filosofía del Derecho Contemporánea, Murcia, Universidad de Murcia.

López de Ayala, don I. (1798): El sacrosanto yecuménico concilio de Trento, Cuarta Edición, Madrid, Imprenta de Ramón Ruiz.

Loreto López, R. (1990a): “La fundación del Convento de la Concepción. Identidad y familias en la sociedad poblana (1593-1643)", en P. Gonzalbo Aizpuru ed., Familias novohispanas, Siglos XVI al XIX, México, El Colegio de México, pp. 163-180

Loreto López, R. (1990b): “Familias y conventos en Puebla de los Ángeles durante las reformas borbónicas: los cambios del siglo XVIII", Anuario del IHES, 5, pp. 31-50.

Loreto López, R. (2000): Los conventos femeninos y el mundo urbano de la Puebla de los Ángeles del siglo XVIII, México, El Colegio de México.

Martínez, M. E. (2008): Genealogical Fictions. Limpieza de Sangre, Religion, and Gender in Colonial Mexico, Stanford, Stanford University Press,

Mujía, R. (1887): "Recurso de Nulidad entablado por la parte de los herederos del finado D. Juan José Chopitea”, Sucre, Tipografía del Cruzado.

Muriel, J. (1946): Conventos de monjas en Nueva España, Editorial Santiago, México.

Presta, A. M. (1997): “Detrás de la mejor dote, una encomienda. Hijas y viudas de la primera generación de encomenderos en el mercado matrimonial de Charcas, 1534-1548”, Andes, 8, pp. 27-46. 
Presta, A. M. (2000a): Encomienda, familia y negocios en Charcas colonial. Los encomenderos de La Plata, 15501600, Lima, Instituto de Estudios Peruanos-Banco Central de Reserva del Perú.

Presta, A. M. (2000b): “Portraits of Four Elite Women: Traditional Female Roles and Transgressions in Colonial Elite Families in Charcas, 1550-1600", Colonial Latin American Review, 9(2), pp. 237-262.

Presta, A. M. (2014): “De la opulencia y la comodidad al ultraje y el olvido. Doña Juana de Zárate, su próspera vida en Charcas y sus desvelos y avatares frente a la fundación de Buenos Aires”, en Mónica M. Ghirardi ed., Territorios de lo Cotidiano, Rosario, Prohistoria Ediciones, pp. 24-32.

Presta, A. M. (2016): “De casadas a divorciadas. Separaciones, divorcios y nulidades matrimoniales en la sociedad colonial, Audiencia de Charcas, 1595-1640", Revista Complutense de Historia de América, 42, pp. 97-118.

Presta, A. M. (2019): “Una elite colonial y sus monjas. Familia y redes en un monasterio de Charcas (15741629)", Travesía, 21(2), pp. 13-36.

Presta, A. M. (2020): “Gobierno colonial y gobierno conventual, jerarquías y redes sociales. Una mirada a la sociedad charqueña y al Monasterio de Nuestra Señora de Los Remedios de Santa Mónica de la ciudad de La Plata, 1584-1600", Diálogo Andino, en prensa.

Reder Gadow, M. (2000): “Las voces silenciadas de los claustros de clausura", Cuadernos de Historia Moderna, 25, monográfico, pp. 279-338.
Reyna Reyes, A. (2015): Carmelitas Descalzas de Santa Teresa en la Villa Imperial, Potosí, Gobierno Municipal de Potosí.

Sánchez Lora, J. L. (1988): Mujeres, conventos y formas de religiosidad barroca, Madrid, Fundación Universitaria Española.

Sánchez Pérez, E. OSA. (2011): “Convento de Nuestra Señora de los Remedios. Agustinas de Potosí (Bolivia)”, en Actas del Simposio La clausura femenina en el Mundo Hispánico: una fidelidad secular (XIX Edición), San Lorenzo del Escorial, Vol. 2, pp. 1095-1128.

Sánchez Pérez, E. OSA. (2013) “Libro de Profesiones del Monasterio de Ntra. Sra. de los Remedios de Agustinas contemplativas de Sucre (Bolivia), y otros activos culturales", en Actas del Simposio Patrimonio Inmaterial de la Cultura Cristiana, San Lorenzo del Escorial, pp. 843-860.

Sánchez Pérez, E. OSA. (2014): “Testamentos de monjas agustinas del Convento de Ntra. Sra. de los Remedios de Sucre (Bolivia). Muerte jurídica por la Vida Eterna", en Actas del Simposio El mundo de los difuntos: culto, cofradías y tradiciones, San Lorenzo del Escorial, vol. 2, pp. 755-772.

Sanz de Bremond y Mayáns, A. (2000): "La libertad de profesión en los claustros femeninos en la Edad Moderna: el proceso de nulidad de profesión de sor Isabel Mancho". Hispania Sacra 52:105, pp. 403-413.

Soeiro, S. (1974): “The Social and economic Role of the Convent: Women and Nuns in Colonial Bahia, 1677-1800", Hispanic American Historical Review, 54(2), pp. 209-232. 
Soeiro, S. (1978): “The Feminine Orders in Colonial Bahia, Brazil: Economic, Social, and Demographic Implilcations, 1677-1800", en A. Lavrin ed., Latin American Women. Historical Perspectives, Westport, Conn.: Greenwood Press, pp. 173-197.

Stone, L. (1965): The Crisis of the Aristocracy, 15581641, Oxford, Clarendon Press.

Thórrez, B. N. (2000): “Algunos temas de la vida musical en el Monasterio de S. Clara de La Plata (16391809)", Anuario de la Academia Boliviana de Historia Eclesiástica, 6, pp. 123-147.

Thórrez, B. N. (2001): “La celda y la vida en común en el Monasterio de Santa Clara de La Plata", Anuario de la Academia Boliviana de Historia Eclesiástica, 7, pp. 81-88.

Triano Panadero, M. A. (1999): “Función económica de los monasterios de clausura en la audiencia de Charcas”, en M. I. Viforcos Marinas y J. Paniagua Pérez, coords., Actas del I Congreso Internacional del Monacato Femenino en España, Portugal y America, 1492-1992, Vol. 1, León, Universidad de León, pp. 441-452.

Van Deusen, N. (2001): Between the Sacred and the Worldly: the Institutional andCultural Practice of Recogimiento in Colonial Lima, Stanford, Stanford UniversityPress.

Vigil, M. (1994): La vida de las mujeres en los siglos XVI y XVII, Madrid, Siglo XXI.

Viforcos Marinas, M. I. (1995): “Las reformas disciplinares de Trento y la realidad de la vida monástica en el Perú virreinal", en M. Ramos Medina coord., Actas del II Congreso Internacional: El monacatofemenino en el imperio español: Monasterios, beaterios, recogimientos y colegios, México, Condumex, pp. 523-539.

Zegarra López, D. E. (1985): Monasterio de Santa Catalina de Sena de Arequipa y Doña Ana de Monteagudo, priora, Arequipa, Corporación Departamental de Desarrollo de Arequipa.

\section{Notas}

1Esta investigación comenzó en 2017 durante mi residencia en el Internationalen Kolleg Morphomata de la Universität zu Köln, Alemania. Las fuentes se recolectaron durante décadas con la financiación del CONICET, la Universidad de Buenos Aires y la Agencia de Promoción Científica y Tecnológica de la República Argentina.

${ }^{2}$ La producción sobre los monasterios femeninos es copiosa y sostenida. Destacan aquí obras que marcaron los inicios del abordaje en determinados espacios coloniales, en los cuales los autores y autoras citados, y quienes los prosiguieron en la temática, registran una prolífica producción imposible de condensar aquí. La síntesis surge a propósito de los objetivos de este artículo que, a su vez, se enmarcó en los lineamientos de la Mesa 8, "Charcas en los Estudios Coloniales. Avances, balances y perspectivas tras los últimos 20 años de producción intelectual" que tuvo lugar en el IX Congreso de la Asociación de Estudios Bolivianos celebrado en Sucre entre el 22 y 26 de Julio de 2019.

${ }^{3} \mathrm{AGI}$ (Archivo General de Indias) Charcas 78, $\mathrm{N}^{\circ} 24$; AGI Charcas 418, L. 1.

4ABNB EP (Archivo y Biblioteca Nacionales de Bolivia, Escrituras Públicas) Vol. 19 Juan García Torrico - La 
Plata, 5.07.1582, f. 660v.

${ }^{5}$ Mujeres que encaraban el divorcio de sus esposos ingresaban voluntaria y transitoriamente al convento a fin de evitar presiones y distancia de quienes buscaban presionarlas para revertir sus decisiones hasta tanto se expidiera la autoridad eclesiástica (Presta, 2016).

${ }^{6}$ ABNB EP 71 Alonso Fernández Michel - La Plata, 4.09.1602, fs. $680-681 \mathrm{v}$.

7ABNB EP 63 Juan Fernández de Castro - La Plata, 6.10.1603, fs. 563-v. Bajo la figura de la exclamación se entiende la expresión lingüística de una emoción, de un sentimiento individual, cuya intención es verbalizar una solicitud, un deseo, una exhortación, aludiendo y comprometiendo solo a quien la invoca (López Hernández, 2005: 115).

8ABNB EP 100 Agustín de Herrera - La Plata, 4.06.1604, fs. 352-357.

${ }^{9}$ ABNB EP 100 Agustín de Herrera-La Plata, 17.02.1605, fs.492v-493r. Cursiva, nuestra.

10ABNB EP 125 Gaspar Núñez de Chaves - La Plata, 29.03.1607, fs. 154v-155v; ABNB EP 140 Juan de Loarte - La Plata, 11.03.1607, fs. 75-v

11ABNB, EP 174 Andrés González de Cavia - La Plata, 24.05.1612, fs. $229 \mathrm{v}-230 \mathrm{v}$

12 ABNB EP 194 Alonso Centeno - La Plata, 24.10.1640, fs. $409 \mathrm{v}-410 \mathrm{v}$.

${ }^{13}$ ABNB EP 217 Diego de Toledo - La Plata, 4.04.1644, fs. $42 \mathrm{r}-\mathrm{v}$.
14ABNB, EP 63 Diego Sánchez - La Plata, 4.03.1597, fs. 55v-58v. Se nombraba hijos "naturales" a los nacidos fuera del matrimonio y de padres no sujetos a vínculo alguno. Si alguno de los padres hubiera estado casado, el descendiente ingresaba al rango de adulterino o bastardo. Generalmente, las hijas naturales de la primera generación fueron reconocidas por sus padres españoles aunque, para la ley, eran ilegítimas por haberse procreado y nacido fuera del sacramento del matrimonio (Ares Queija, 2004). Si legitimados legalmente, los hijos naturales tuvieron dispar suerte en el acceso a la herencia de sus padres, sobre todo a encomiendas y títulos. Las hijas naturales de los conquistadores licuaron su ilegitimidad, e ingresaron al mercado matrimonial como españolas al haberse criado en casa de sus progenitores y en los valores y religión cristiana. Algunas, como doña Juana de Zárate fueron legitimadas por el rey Felipe II, aunque la mácula de origen no pudo borrar la inquina y el desdén de las autoridades que hicieron caso omiso a su condición y hasta intentaron desconocer su matrimonio con un ex oidor de Charcas (Presta, 2014).

15ABNB, EP 142 Alonso Fernández Michel - La Plata, 12.05.1607, fs. 359r-360v.

16ABNB EP Vol. 128 Gaspar Núñez-La Plata, 22.06.1611, fs. 206-v.

17ABNB EP 84 Alonso Fernández Michel - La Plata, 10.01.1618, fs. 182-188v; ABNB, EP 151 Alonso Fernández Michel - La Plata, 21.02.1618, fs. 712v-714v.

18ABNB EP 140 Juan de Loarte - La Plata, 10.08.1611, fs. 229-230; ABNB EP 336b s/f, fs. 228-229v.

${ }^{19}$ ABNB EP 51 Francisco de Tovar- La Plata, 2.10.1597, 
s/f; ABNB EP 73 Luis de Sarría - La Plata, 15.10.1604, fs. 599-601v; ABNB EP 140 Juan de Loarte - La Plata 10.08.1611, fs. 229-230; ABNB, EP 151 Alonso Fernández Michel-La Plata, 21.02.1618, fs. 708r-712r; ABNB, EP 151 Alonso Fernández Michel - La Plata, 21.03.1618, fs. 708r-712r; ABNB, EP 120 Agustín de Herrera - La Plata, 22.06.1626, fs. 732r-737v.

20ABNB EP 19 Juan García Torrico-La Plata, 22.11.1582, fs. 1110v-112r. La suma no era significativa y alcanzaría para adquirir una casa de morada en la ciudad con escaso mobiliario y enseres. Las dotes de las doncellas de elite sobrepasaban los 30.000 ensayados, como la de la prima de doña Jerónima, doña María de Peñalosa, hija del licenciado Polo Ondegardo.

21AGI, Escribanía 844B. La Plata año de 1586, fs. 578r-579v; 817r-824v.

${ }^{22}$ AGI, Escribanía 844B. La Plata año de 1586, fs. 18v; 231r; 455r-v; Presta, 2019: 21-22. 